\title{
Blurring boundaries in cultural tourism research
}

\author{
Esther Binkhorst, Teun den Dekker and Marjan Melkert
}

\section{Introduction}

Tourism development is often hindered by the way tourism is claimed and framed. Driven by an economic growth perspective, tourism developers and policy makers allow tourism to increase, laying claim to natural, social, cultural, historical and other resources. We argue here that the starting point for tourism development should be human beings and their time-spatial context. This humanistic vision is very much inspired by the ethnographic perspective. For tourism this implies an innovative approach. It means doing away with distinctions between supply and demand, company and customer, tourist and host, tourism and non-tourism spaces. Instead we should view tourism as a holistic network of actors connected in experience environments and operating within different time-spatial contexts (Binkhorst and Den Dekker, 2009). A central role for the human being and thinking in experience networks are needed all the more so because of the blurring of boundaries between tourism, art, culture, sport, hobbies and learning, which are hard to deal with using traditional research approaches. When is someone actually a tourist? When is someone a cultural tourist? What hobbies, activities and experiences are considered to be (cultural) tourism experiences? Is it possible to distinguish between someone's cultural (tourism) activities and other (tourism) activities? How can tourists as human beings best be studied in an era of blurring boundaries? The aim of this chapter is to explore potential new ways of researching cultural tourism.

\section{The Tourist as Human Being}

\section{Tourism experience networks}

The essential information necessary to understand tourism phenomena and to be able to develop tourism is hidden in each human being who becomes a tourist or who, in one of his or her experience environments, comes into contact with tourism. A tourism network approach allows us to understand the interaction between individual tourists and other actors as well, in other words anyone and anything involved in the tourism network.

In tourism, the 'experience environment' is made up of all the people and things that surround the tourist. This not only includes the time when people are actually travelling but also the period in which the decision to travel is taken and the post-travel period after returning home. Consequently each person is surrounded by a unique 'tourism experience network' of all the stakeholders involved in his or her tourism experiences, whether they are real, virtual or even imaginary. The argument made here is that we should define tourism as an experience network in which various actors co-create as they engage in tourism experiences. This relates very much to what van der Duim (2007) called 'tourismscapes', or the complex processes of ordering of people and things. Such tourism experience networks are immense and connect the human being with: the people they travel with (friends, partner, family, special- interest group, colleagues), the Internet, virtual travel communities, travel agencies, tour operators, suppliers of transport, hoteliers, guides, local entrepreneurs offering activities at the destination, local residents, sights and activities at the destination such as attractions, typical landmarks, museums, heritage sites, events, natural landscapes, technology and so on. Tourismscapes also include the governmental and non-governmental agencies that shape the conditions of travel. Figure 1 provides a simple representation of such a tourism experience network.

The tourism experience network approach forces us to put the human being at the centre, not as a tourist but as a human being. In the fi rst place, any tourist is a person or actor in his or her home environment (see Fig. 2). This is where he or she will usually spend most of the time and where lots of memorable social experiences will be undergone. In the home environment, people also spend much time on obligations such as work and school. The network in which the person acts basically guides him or her through life and will also respond to life's changes. The need for a tourism experience might evolve at a certain moment, which consequently changes 
the person's network. New actors will be sought or links with existing actors will be strengthened to achieve one's objectives to fulfil the need to travel (see Fig. 3). Once the person has been through the travel decision-making process he or she will leave the daily experience environment for a holiday or a break (see Fig. 4) and will return again to the home environment after travel (see Fig. 2). The first two experience environments, the home environment and the work and/or learning environment, are often neglected in tourism studies.

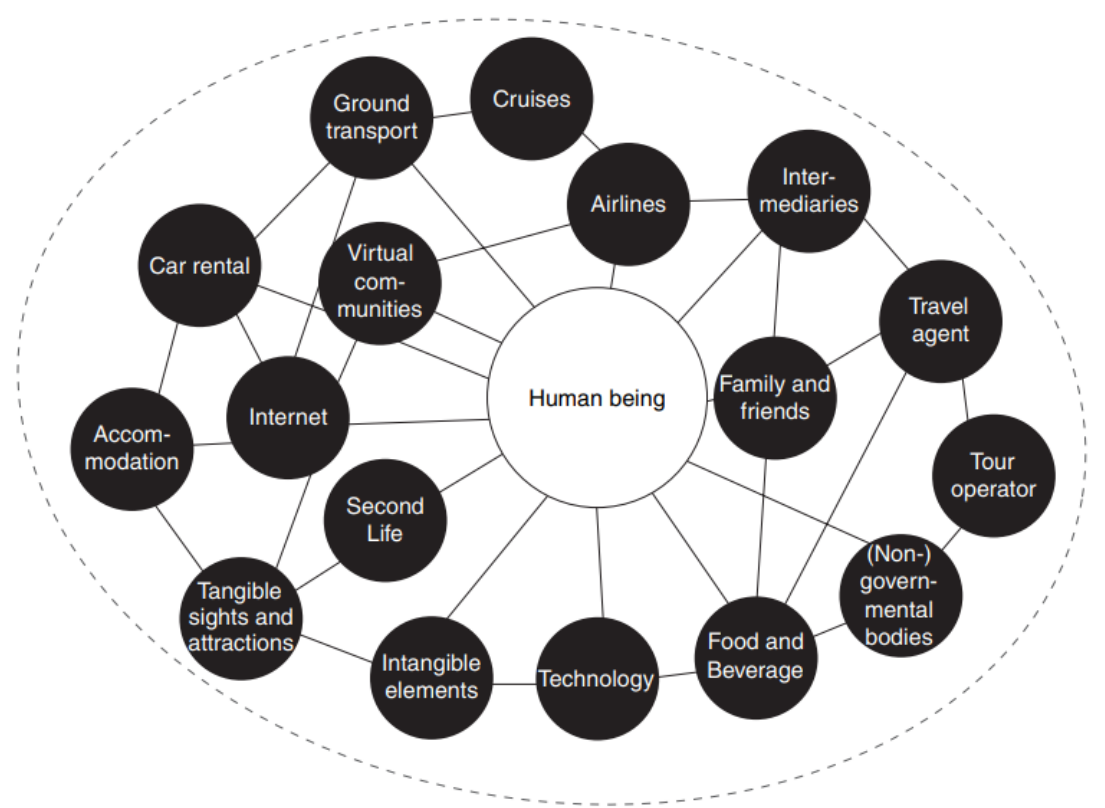

Fig. 1. Tourism experience networks. (Source: Binkhorst and Den Dekker, 2009.)

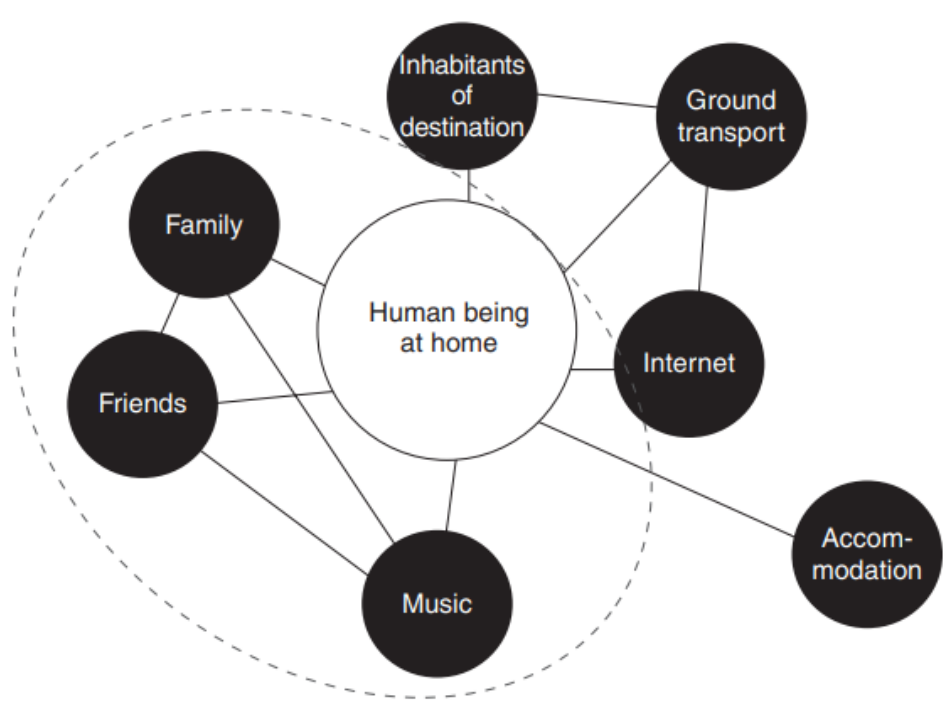

Fig. 2. Experience network of the home environment. (Source: Binkhorst and Den Dekker, 2009.) 


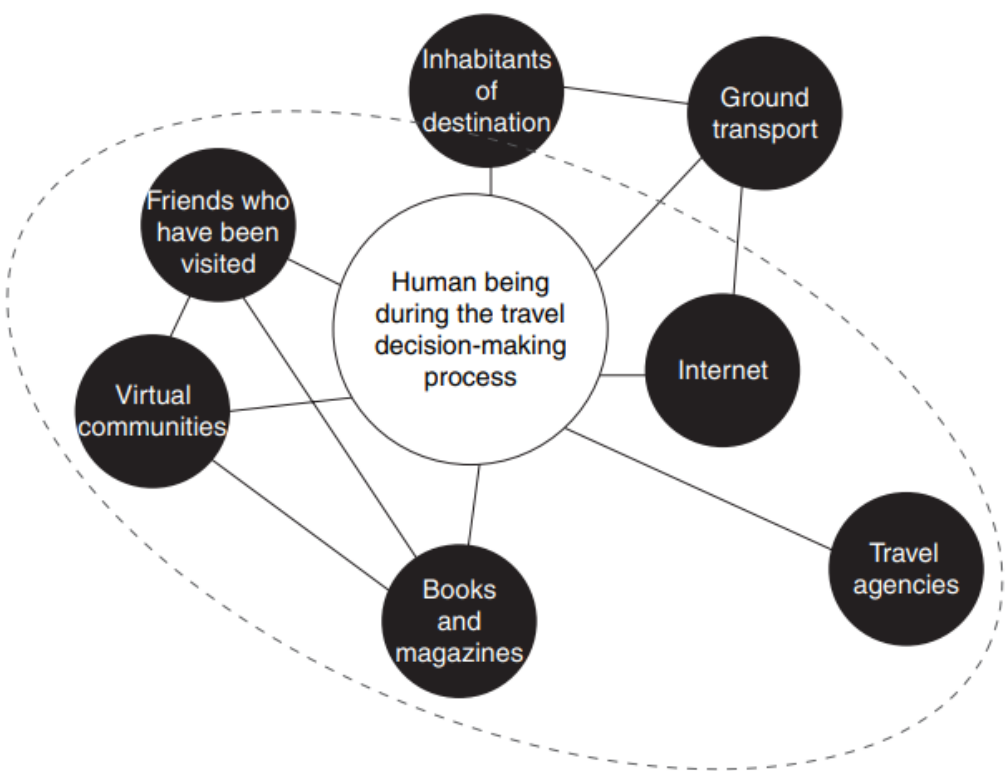

Fig. 3. Experience environment during the travel decision-making process. (Source: Binkhorst and Den Dekker, 2009.)

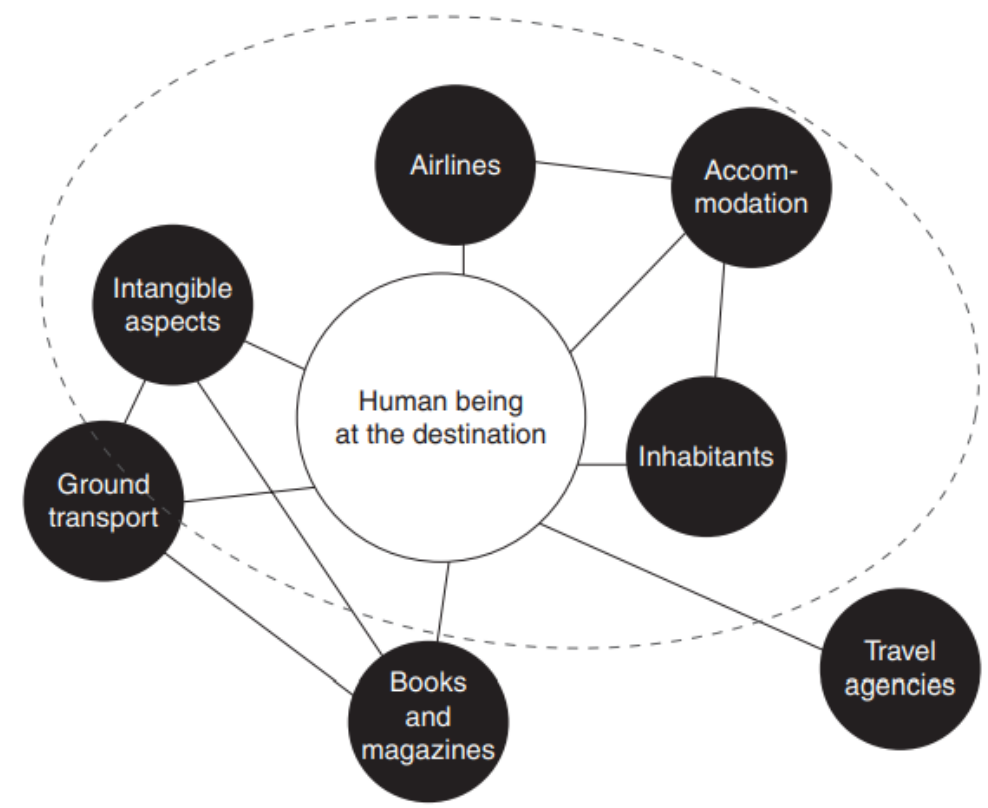

Fig. 4. Experience network at the destination. (Source: Binkhorst and Den Dekker, 2009.)

When picturing a tourist, researchers routinely begin with an image of someone in the third experience environment, that of free time, characterized by the freedom, time and money to travel to other areas outside the daily living environment. Moreover, they tend to imagine the tourist either when travelling to or being at the destination. We do not usually consider persons as a 'tourist' while they are still in their own daily context. But the daily context is exactly where a 'tourist' spends most of the time and where decisions are taken about future trips and where a lifestyle might influence a travel style. Certain newspapers and magazines drop regularly into the 'tourist's' mailbox; certain TV channels are watched; donations to certain organizations are made; certain souvenirs in the home environment and clothes in the wardrobe remind us of previous trips; books, CDs and DVDs on the shelves tell us about art, culture, music, painting, pottery, history, travel destinations; favourite bars, restaurants or clubs are visited; certain 
websites connect the 'tourist' through the Internet with the rest of the world; stories and experiences are exchanged with family members, colleagues and friends; and a certain type of work or education shapes 'the tourist's' life. By studying the various experience environments in their daily context, researchers could get to know the tourist better, or, more accurately, the human being behind the tourist. The following sections examine how the study of tourism is complicated by questions of subjectivity and objectivity. We then examine the case for striking a balance between these two extremes and finally we provide some examples of potentially innovative approaches to researching the increasingly blurred world of the tourist.

\section{The Cultural Tourism Product: the Subjectivist versus the Objectivist Approach}

\section{How can we defi ne culture?}

If blurring of boundaries leads us to regard and research the cultural tourist as a human being, then what will this process mean for the object or the cultural experience? Well, nothing new to start with. As Richards (1996: 42) remarks: 'One of the few areas of certainty in cultural tourism is the difficulty of defining it. Few studies are agreed about what the cultural element of cultural tourism should encompass'. The best way to proceed is therefore to try to find out what is meant by the term 'culture' itself in different contexts. Richards (1996) explains that culture can refer to a process or a product. The idea of culture as a process stems from anthropology and sociology. Codes of conduct that are embedded in a specific group define what culture is for that group. Culture is therefore the process through which people make sense of themselves and their lives. An example of this is the music CD that a tourist may bring home having attended a dance performance on holiday. Hearing it at home will probably not evoke the same kind of experience, because of the change in context.

The idea of culture as a product was developed within art criticism. The cultural product is the result of individual or group activities to which certain meanings are attached. These meanings can define something as 'high' or 'low' culture. The definitions of high and low culture evolve continuously, as is noted and described within postmodern discourse. An illustrative example is offered by the new policy of the British Museum welcoming back its anthropological collections and even staging special events connected with them, such as modelling and worshipping a clay Hindu goddess in the museum. Several decennia ago, the same collections would have been removed from this temple of high culture and such events would have been labelled as popular culture.

Because of all these uncertainties, it may be more sensible, as an aid to understanding why what is being said where, to consider the matter from the point of view of the philosophy of values. The ontological status of values depends on the question if values exist in their own right or if they exist only if there is an evaluating entity. Therefore the status of values depends on the context in which they are seen - the general outlook on life - and whether this is subjective or objective. In other words: is it an entity - a human being - that evaluates the world or are there immanent values to be found in the world itself?

\section{Subjectivism}

Radical subjectivity implies that the point of reference is the subject, in this case the cultural tourist. The subject attaches values to things. Since this is a human act, it is the behaviour of the human being which has to be studied in order to understand personal preferences relating to specific - in this case cultural - objects and experiences. In the subjective picture of the world, again, values do not exist independently in themselves. Objects that are evaluated positively are those that are desirable for the subject. The subject constructs the values and these do not depend on a correspondence with reality. Subjectivists argue that if there were no evaluating subjects, there would be no values. The seven different subsets or niche components that Smith (2003) identifies with the term 'cultural tourism' can be related to the subjective preferences or profile of the cultural tourist. 
1. The tourist who likes heritage visits castles, palaces, country houses, archaeological sites, monuments, architecture, museums and religious sites.

2. The tourist who likes arts visits the theatre, concerts, galleries, festivals, carnivals, events and literary sites.

3. The tourist who likes to be creatively engaged will undertake photography, painting, pottery, cookery, crafts and language learning.

4. The tourist who likes urban culture will visit historic cities, regenerated industrial cities, waterfront developments, arts and heritage attractions.

5. The tourist who likes rural culture will visit villages, farms and agro-tourism objects, ecomuseums, national parks and follow wine trails.

6. The tourist who likes indigenous culture will visit hill tribes and participate in desert or mountain trekking. They will also visit cultural centres and be interested in arts and crafts products, cultural performances and festivals.

7. The tourist who likes popular culture will visit theme parks and theme attractions, shopping malls, pop concerts, sporting events, media and fi Im sets, industrial heritage sites and fashion and design museums.

Once the tourist has been identified as the subject who 'makes' the cultural tourism product, the boundaries between these different types of products blur. Because the cultural tourist is a human being with various preferences, he or she will choose, combine and mix the components of the cultural tourism product in accordance with his or her needs and wants. So a wide range of different tourist experiences may be sought by the same individual: swimming in a river in the morning, visiting a temple in the afternoon and dancing at a beach party at night. This goes especially for the postmodern tourist consumer belonging to the 'zap' generation, whose behaviour is as eclectic as it is unpredictable.

According to Schouten (2003), what the visitor wants (to experience) should be interesting, unique and meaningful. That is why interpretation and imagination play an important role in presenting the cultural tourism product. But what about the authenticity of the cultural object or event? By stating that authenticity is determined by the visitors themselves, Gilmore and Pine (2007) take an extreme subjectivist position in the debate on this issue. The danger of this subjectivist point of view is that the focus on personal preferences of the tourist may lead to the commodification of culture on the one hand and cultural relativism on the other.

The value that the subject attaches to an object or the intrinsic value of an object is not the same as its moral value. Moral implications can only be found within a theory of moral obligations, where objects become moral objects. The way in which a moral object is treated can be judged as good or bad. In eco-philosophy, ecosystems are regarded as moral objects. Cultural objects too are often regarded as moral objects, as indicated by all the measures taken to prevent cultural heritage from crumbling under the pressure of too many tourists and the use of the money these visitors bring in for restoration. So dealing morally with cultural objects can be described in terms of preservation and development, two processes that are frequently analysed in cultural tourism studies. A good example is the cultural tourism sustainability mix developed by Munsters (2005): preservation (of the cultural object), population (the interests of the host community), public (the experience of the cultural tourist) and profit (for the tourism industry) should be in balance, in order to guarantee the sound development of cultural tourism.

\section{Objectivism}

The opposite philosophical stream to subjectivism is objectivism. For this school of thought everything begins with the object. From an objective perspective the point of reference is the set of characteristics of the object observed. The object is valued because of its intrinsic values. Values here are not a function of human desire, but they exist in their own right as the characteristics of the object and independent of the presence of an evaluating entity, because reality contains much more than we can consciously conceive. In this outlook on reality, the (tourist) subject does not attach value to an object but rather discovers it. The cultural tourist visits cultural objects or events in order to enjoy their immanent qualities. The characteristics are the things that enable us to evaluate an object. 
Munsters (2007) makes it very clear that a cultural object, event or spectacle has to be open for the public in order to be able to become a cultural tourism product. The attractive value is primarily being defined in terms of the measure of accessibility. The characteristics the cultural offer possesses sui generis are secondary. Munsters' $(1996,2007)$ general typology of cultural tourism resources, categorized into attractions (permanent by definition) and events (temporary by definition), may be qualified as objectivist or ideographic, as it is based on the attributes of the cultural resources (Richards, 2001) (Box 1).

Box 1. General typology of cultural tourism resources. (Source: Richards, 1996: 110.)

\begin{tabular}{|c|c|}
\hline \multicolumn{2}{|c|}{ 1. Attractions } \\
\hline \multicolumn{2}{|c|}{ (a) Monuments } \\
\hline & Religious buildings \\
\hline & Public buildings \\
\hline & Historic houses \\
\hline & Castles and palaces \\
\hline & Parks and gardens Defences \\
\hline & Archaeological sites \\
\hline & ndustrial-archaeological buildings \\
\hline \multicolumn{2}{|l|}{ (b) Museums } \\
\hline & =olklore museums \\
\hline & Art museums \\
\hline \multicolumn{2}{|l|}{ (c) Routes } \\
\hline & Cultural-historic routes \\
\hline & Art routes \\
\hline \multicolumn{2}{|c|}{ (d) Theme parks } \\
\hline & Cultural-historic parks \\
\hline & Archaeological parks \\
\hline & Architecture parks \\
\hline \multicolumn{2}{|l|}{ 2. Events } \\
\hline \multicolumn{2}{|c|}{ (a) Cultural-historic events } \\
\hline & Religious festivals \\
\hline & Secular festivals \\
\hline & Folk festivals \\
\hline \multicolumn{2}{|l|}{ (b) Art events } \\
\hline & Art exhibitions \\
\hline & Art festivals \\
\hline \multicolumn{2}{|c|}{ (c) Events and attractions } \\
\hline & Open monument days \\
\hline
\end{tabular}

From the objectivistic point of view, knowledge of an object and taking the time to get to know it are of paramount importance for an adequate evaluation. Lack of knowledge makes the judgment of value unreliable. In the objectivistic perspective on reality, taste becomes something that can be disputed while education is considered as crucial for the improvement of the ability to evaluate things. This point of view risks attracting the reproach of elitism. Schouten (2005) calls it the 'what the expert says' aspect of cultural tourism: the conservator and the restorer of cultural heritage qualify their activities in terms such as 'important', 'significant', 'relevant', 'content', 'facts' and 'history'. Experts prefer a public of connoisseurs of art and history and they have a negative opinion of tourists. The gap that may result from this line of thought is also felt by the general public when art and heritage presentations do not match with their interests. 
In the discussion on authenticity, objectivists hold totally opposite views to subjectivists. With regard to the authenticity of historic buildings, Denslagen (2004) feels it is confusing that different meanings become attached to the term 'authentic'. This Tower of Babel evaporates the content of the term and leads to a practice of 'anything goes'. His advice is to make a clear distinction between 'authenticity' and 'originality'. The authentic is the historic object itself, regardless of wear, tear and change. The original is the state in which the object was first presented. Only the substance of an object, work of art or building can be authentic and nothing else. At the 1994 conference of the International Council of Monuments and Sites in Japan, it was decided that besides the material authenticity of the (historic) substance it should be possible to label other things as authentic too. Denslagen mentions the continuity of local definitions of cultural heritage and local restoration traditions as examples. This theory may well apply to historic buildings and artefacts, but it falls short for the performing arts. Before the pianola and the wax roll were developed, it was difficult to tell what a piece of music sounded like. Until then, music notation systems put on paper what should reverberate within the ear of the listener. Therefore one of the great artistic experiences has been the study and performance of the 'Alte Musik Tradition', (i.e. medieval, Renaissance and Baroque music). Since Vivaldi (in 1958) and Bach (in 1964) have been played on historical instruments, musicologists have been working hard to find out how music originally was performed, on what instruments, in what sort of architectural environment, for what sort of audience(s) and trying to relive those experiences. The authenticity of the performance remains a point of discussion, but the advice of the singer Marco Beasley (2005) to take the heart as one's guide may be the best direction to follow here, even if this seems 'unscientific'.

\section{Virtus in medio}

Subjectivism and objectivism are radically different approaches to reality. However, as Melkert and Vos argue in Chapter 3, they do not necessarily exclude each other. It is possible to give a place to evaluating subjects within a world where objects have intrinsic values and to realize an exchange between subjects and objects according to Horace's words: virtus est medium vitiorum et utrimque reductum (virtue is the middle between two vices, and is equally removed from either extreme).

It is clearly beneficial for the study of cultural tourism products if researchers are well aware of their position and that of their fellow researchers within the fi eld of tension between subjectivism and objectivism. This awareness would enable them to understand who says what with regard to the cultural tourism product. The approach of sociologists, anthropologists and art critics, who see culture either as a process or as a product, puts them on the subjective side of the spectrum. Nevertheless, within their field of study, an objective approach could also be possible and might even help to change interpretations. The place in the middle may also be the place where experts meet exploiters and where cooperation is possible between these two sides in the process of cultural tourism product development.

The question of what is authentic 'in the middle' may create, as in the case of the 'Alte Musik Tradition', a true 'battlefield' of expectations, new discoveries and incessantly growing insights. The conclusion might even be that it is impossible to define what is authentic at all. The quest for a definition of authenticity may even be destructive, as Hildesheimer (1985) claims in Der ferne Bach, because it stands in the way of new interpretations. Nevertheless, the performers of ancient music present the world with a breathtaking series of rehearsals, concerts and audio recordings that either enchant or provoke disgust and that set hearts and minds at work. A case of fertile, even procreative, misunderstanding? Admirers of ancient music become cultural tourists as they travel to the historic castles, convents and churches and other places where the concerts take place. Films like Corneau's Tous les matins du monde and Corbiau's Farinelli - il castrato and Le Roi danse have made the results of the quest accessible for a larger audience. These films may even be an incentive to visit the remains of the architectural decor they evoke (such as Versailles) and can so produce a spin-off in the form of cultural tourism. 
Claiming this middle ground requires us to put ourselves in the position of the tourist, and to place the tourist as human being at the centre of the tourism experience. The problem with this new positioning is the difficultly of capturing the new insights generated using traditional tourism research methods. We would argue, therefore, that what is needed is a new range of research tools capable of traversing the middle ground and seeking out the innovative behaviours and experiences of the tourist. In the following section we outline some innovative new ways of approaching the tourist, which may provide a means to capture new dimensions of their experience.

\section{Developments in Methodological Innovation}

If we want to acknowledge the tourist as human being in an experience environment, new research methods are needed to be able to understand tourist behaviour better. Conventional research methods can be sufficient to describe and register tourism behaviour, but when researchers really want to understand the tourist as a human being, innovative methods are required to explore the experience environments and how these are used by the tourist. Two main developments can be distinguished in innovative methods. First, a shift from top-down to bottom-up approaches, with dialogues between equal partners taking the place of traditional topdown methods. Second, a shift can be observed from real to virtual methods. The use of virtual worlds such as Second Life is becoming common in tourism, as it is in other areas of social life. These tools provide numerous innovative ways of doing both qualitative and quantitative research.

Figure 5 shows a wide range of research methods, from the more conventional methods at the bottom to the more inno vative at the top. The most innovative of these methods will be explained with the help of illustrative cases from tourism and other fields.

\section{The use of websites as a research tool: the case of IKEA in the Netherlands}

The central theme of a Dutch website initiated by IKEA is 'Design Your Own Life'. The website aims at getting insight into the way people shape their own lives and enjoy living. Consumer research by the market research company TNS-NIPO forms the basis of the website. Visitors can discuss topics on a forum, do tests, read advice and in the process learn more about themselves. IKEA as a company can learn a lot from the input visitors provide. As an example of an instrument used to gather visitor information by means of a bottom-up approach, this tool is also perfectly aplicable within the framework of tourism destination management.

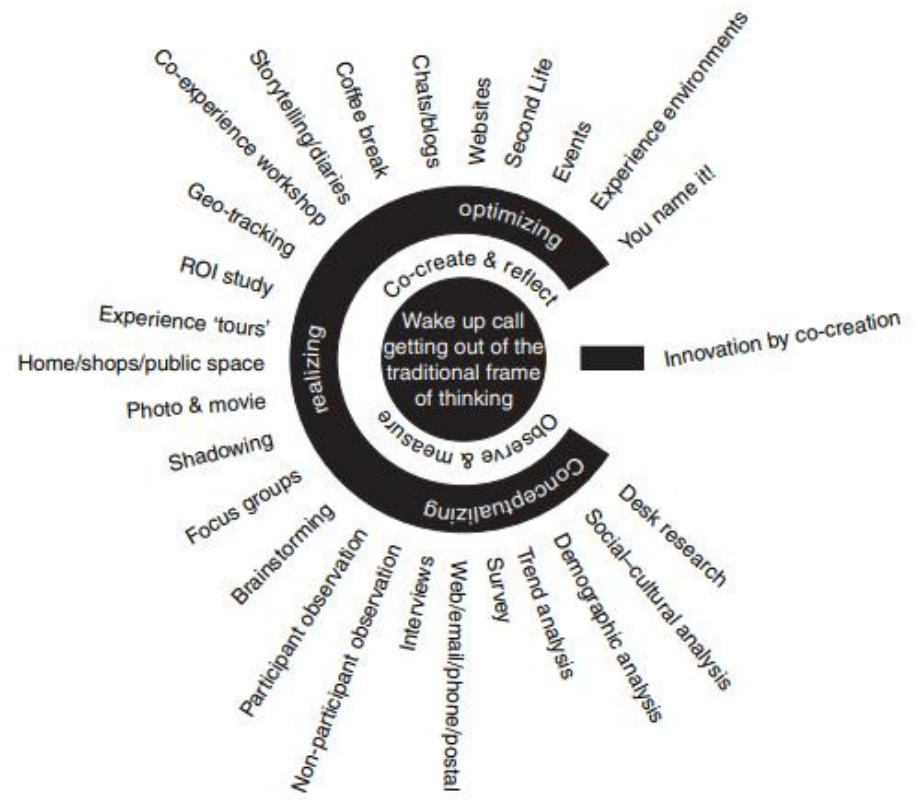

Fig. 5. Research methods. (Source: Co-Creations S.I.) 


\section{The use of geo-tracking: the case of Ipoki, Spain}

Geo-tracking takes the investigation of human spatial behaviour to a more sophisticated level. New technologies provide researchers with other possibilities to track tourists during their journey. Today there are two main tracking technologies available: satellite navigation systems and land-based navigations systems (Shoval and Isaacson, 2007). Through the Spanish social network Ipoki (http://www.ipoki.es), geo-tracking is available for everyone. Ipoki members can trace the movements of their friends through GPS software downloaded to their mobile phones. By creating an lpoki group among tourists, it should also be possible to monitor tourist movements without the need for sophisticated hardware. Recent developments and new models in the mobile phone industry make geo-tracking via GPS even more easy and accessible.

\section{The use of experience environments: the case of the Co-lab in Sitges, Spain}

The Co-lab is an apartment-cum-office in the Spanish coastal village of Sitges, where tourism practice and research go hand in hand. A type of tourism based on the principle of cocreation has been developed there to showcase the possibilities for innovation in tourism development (Binkhorst, 2007). This means, on the one hand, that locals participate in enhancing the experience of the tourist and, on the other hand, the tourists themselves can play an active role in the co-creation of their tourism experiences. At present, real-life experiences are being developed, and the next step will be to create an experience environment in which both tourists and locals can also virtually shape and share their experiences. At the same time a data collection tool will be developed. In addition to the traditional questionnaire and (in-depth) interview, one of the research methods used in the Co-lab to gain insight into how tourists experience the destination and their holiday in general is to have them picture their holiday through their own eyes during the 'do it yourself tour'. The data will be used to create a (virtual) book written or, better said, pictured by tourists about their holiday and the destination. These data will be shared with anyone whose experience environments they come across.

\section{The use of public space: the case of the New Zealand Travel Café, Tokyo, Japan}

The New Zealand Travel Café in Tokyo, Japan, is a public space used to teach Japanese people in an informal way about New Zealand as a tourism destination. Their visit to the Travel Café, which is part of their home environment, has an influence on their travel decision-making process. The Travel Café is an interesting opportunity for the tourism industry and governmental tourism bodies in New Zealand to get in contact with potential visitors before they actually visit the country.

\section{The use of storytelling: the case of Audio Snacks/N8 geluiden in the USA and the Netherlands}

Audio Snacks and N8 geluiden (Sounds of the Night) are similar initiatives from the USA and the Netherlands. The basic concept is that anybody with a sound recording device (such as an MP3 player) can make their own audio guide of a certain destination and can share it through the Web. By tracking download and upload behaviour, researchers can learn a lot about what people tend to seek in a certain destination.

All the examples mentioned above show a similar tendency: the blurring of boundaries between the different experience environments of the tourist. When we acknowledge those blurring boundaries and keep in mind the evolution from top-down to bottom-up and from real to virtual approaches, abundant possibilities are at hand in order to generate a more profound understanding of the behaviour of the tourist as a human being. 


\section{Conclusions}

As the boundaries between different types of consumption become blurred, so it becomes increasingly important to place the tourist at the centre of the tourism system. In this way, the complex connections between different forms of consumption in different types of environments can be traced and interlinked. Collecting data on these new forms of tourist consumption requires new methods that are able to cross the boundaries between home and tourist environments and quantitative and qualitative information. Advances in technology are making such innovative approaches increasingly viable and should open up exciting new avenues for research in the future.

\section{References}

Beasley, M. (2005) A voice, a way. In: Beasley, M. and Morini, G. (eds) Recitar Cantando/Accordone. Cypres Records, Brussels (CD).

Binkhorst, E. (2007) Creativity in tourism experiences, a closer look at Sitges. In: Richards, G. and Wilson, J. (eds) Tourism, Creativity and Development. Routledge, London, pp. 125-145.

Binkhorst, E. and Den Dekker, T. (2009) Agenda for co-creation tourism experience research. Journal of Hospitality Marketing and Management 18, 311-327.

Denslagen, W. (2004) Romantisch Modernisme, Nostalgie in de Monumentenzorg. SUN, Amsterdam.

Gilmore, J.H. and Pine, J. (2007) Authenticity: What Consumers Really Want. Harvard Business School Press, Boston, Massachusetts.

Hildesheimer, W. (1985) Der ferne Bach, 2nd edn. Insel Verlag, Frankfurt am Main, Germany.

Melkert, M. (1995) Within you without you: over objectivistische waardentheorieën en Milieufilosofie. MA thesis. University of Limburg, Maastricht, the Netherlands.

Munsters, W. (1996) Cultural tourism in Belgium. In: Richards, G. (ed.) Cultural Tourism in Europe. CAB International, Wallingford, UK, pp. 109-126.

Munsters, W. (2005) Culture and tourism: from antagonism to synergism. ATLAS Reflections 2005, 41-50.

Munsters, W. (2007) Cultuurtoerisme, 4th edn. Garant, Antwerpen-Apeldoorn, Belgium.

Prahalad, C.K. and Ramaswamy, V. (2003) The new frontier of experience innovation. MIT Sloan Management Review 44, 12-18.

Prahalad, C.K. and Ramaswamy, V. (2004) The Future of Competition: Co-creating Unique Value with Customers. Harvard Business School Press, Boston, Massachusetts.

Richards, G (1996) The scope and significance of cultural tourism. In: Richards, G. (ed.) Cultural Tourism in Europe. CAB International, Wallingford, UK, pp. 19-45.

Richards, G. (2001) The development of cultural tourism in Europe. In: Richards G. (ed.) Cultural Attractions and European Tourism. CAB International, Wallingford, UK, pp. 3-29.

Schouten, F. (2003) About the quality of life, and nothing less. In: Creating a Fascinating World. Breda University of Professional Education (NHTV), Breda, the Netherlands pp. 9-14.

Schouten, F. (2005) Productontwikkeling voor erfgoedtoerisme (weer) in het verdomhoekje. Vrijetijdsstudies 23, 47-50.

Shoval, N. and Isaacson, M. (2007) Tracking tourists in the digital age. Annals of Tourism Research 34, 141-159.

Smith, M.K. (2003) Issues in Cultural Tourism Studies. Routledge, London.

Van der Duim, V.R. (2007) Tourismscapes. An actor-network perspective. Annals of Tourism Research 34(4), 961-976 